\title{
Clinicopathological importance of deposits of amyloid in the femoral head
}

\author{
NRB CARY \\ From the Department of Histopathology and Experimental Pathology, Charing Cross and Westminster \\ Medical School, London
}

SUMMARY The pattern of amyloid deposits in the femoral head is described in four cases, two of which had deposits of amyloid related to age and two of which had generalised systemic amyloidosis (one of primary amyloidosis, one of multiple myeloma). The deposition of amyloid in the articular cartilage of the femoral head was similar in all four cases. Heavy deposits of synovial amyloid were identified in the case with primary amyloidosis and in one of the cases with amyloidosis related to age. Both cases of generalised systemic amyloidosis showed abundant deposits of amyloid in the bone marrow. Amyloid was not present in the bone marrow of either case with amyloidosis related to age. The importance of these findings is discussed in relation to the pathogenesis of the arthropathy syndrome of a rheumatoid type described in cases of primary amyloidosis and multiple myeloma.

Deposits of amyloid in human articular cartilage have been reported in cases of primary amyloidosis ${ }^{1}$ and more recently as a common finding in people over the age of 50 without any evidence of generalised systemic amyloidosis. ${ }^{2-4}$ Nevertheless, this type of deposition was not looked for in a large necropsy study of senile amyloid deposits. ${ }^{5}$

Microdeposition of amyloid in the synovium and periarticular tissues has also been described as a phenomenon related to age, apparently associated with osteoarthritis. ${ }^{46}$ Heavy deposition of amyloid in the synovium and periarticular tissues in primary amyloidosis and multiple myeloma has been recorded in association with an arthropathy of a rheumatoid type..$^{7-11}$ In the cases reviewed by Wiernik the arthropathy was usually symmetrical and affected both large and small joints, those most commonly affected being the shoulders, knees, hips, elbows, wrists and small joints of the hands. "Pain and stiffness were typical symptoms and in many cases there were swellings of palpable soft tissue around the affected joints. Carpal tunnel syndromes were also common. The average age at time of presentation was 51 , and there was a slight predominance of the condition among men.

\section{Patients and methods}

Four cases of amyloidosis of the femoral head were compared. Two patients were elderly and had suffered a traumatic fracture of the femoral neck which had been treated by hip replacement: there was no evidence of generalised systemic amyloidosis. One patient (case 3 ) reported a vague history of several years of aches and pains in joints, including the hips, but there were no features of an arthropathy of a rheumatoid type. In the other patient (case 4) there were no symptoms that could be connected to the hips. Both cases showed only minimal radiographic evidence of osteoarthrosis. The deposits of amyloid were concluded to be a manifestation of ageing.

The other two patients had generalised systemic amyloidosis; one (case 1) had primary amyloidosis, the other (case 2) multiple myeloma. In case 1 there had been over 30 years of pain in both hips. Over the past 18 months the pain had worsened, necessitating confinement to bed. Radiographs at that time had shown bilateral protrusio acetabuli and osteoarthritic changes. There were also small radiotranslucencies in the femoral heads, which, in retrospect, may have been due to deposits of amyloid. With such a long history of hip pain in addition to absence of symptoms in other joints there was nothing to suggest an arthropathy of a rheumatoid type, though the possibility that the recent exacerbation of symptoms in the hips had been caused by superimposed amyloid arthropathy cannot be excluded.

In case 2 , the patient had had nine months of 
bilateral pain and stiffness in the hips, especially in the mornings, which was more pronounced on the left side. In addition, there were bilateral carpal tunnel syndromes and pain and stiffness in the small joints of the hands. Radiographs of the hip joints showed no evidence of osteoarthrosis. There were multiple small radiotranslucencies in the left femoral head, which, in retrospect, had first been apparent two years before the pathological subcapital fracture of the femoral neck had occurred. The features of this case are typical of those found in the arthropathy of a rheumatoid type in generalised systemic amyloidosis.

Representative slices through the complete femoral head, including any attached synovial tissue, were cut perpendicular to the articular surface, decalcified, and processed to blocks of paraffin (case 1 , three blocks, case 3 , five blocks, case 4 , five blocks). In case 2 the femoral head was fragmented, and the various fragments of tissue were embedded to give sections as near perpendicular to the articular surface as possible (three blocks). Sections were cut at about $8 \mu \mathrm{m}$ and stained with haematoxylin and eosin. Amyloid was identified in sections stained with Congo red by apple green birefringence of stained areas in polarised light. The amyloid was classified by pretreatment with potassium permanganate before staining with Congo red ${ }^{12}$ : amyloid $\mathrm{A}$, the major fibrilar protein present in reactive sys- temic amyloidosis, loses its affinity for Congo red after such treatment; amyloid L, the principal fibrilar protein in amyloid associated with immunocyte dyscrasias, is resistant.

Table 1 shows some clinical and pathological features of the cases and Table 2 shows the pathological findings in the femoral head. Figures 1-5 illustrate the patterns of amyloid deposition. All four cases showed a similar pattern of amyloid deposition in articular cartilage. Heavy synovial deposits were present in one of the patients with primary amyloidosis (case 1) and in one of the patients with amyloidosis related to age (case 3 ). No synovial tissue could be identified among infarcted fragments of bone and marrow in the patient with multiple myeloma (case 2). Only the two patients with generalised systemic amyloidosis showed deposits in bone marrow, and these were very heavy. In all instances the deposits of amyloid were mainly or wholly of the AL type.

Samples of articular cartilage were also examined with an electron microscope. In cases 2,3 , and 4 material was processed from tissue embedded in paraffin wax and in case 1 directly from tissue fixed with formalin. In all four cases the presence of amyloid was confirmed. It consisted of a random meshwork of fibrils varying in size from $7 \cdot 5 \mathrm{~nm}-10$ $\mathrm{nm}$ present both as homogenous masses and in admixture with fibres of collagen (Fig. 6).

Table 1 Clinical and radiological features

\begin{tabular}{|c|c|c|c|}
\hline $\begin{array}{l}\text { Relevant clinical and } \\
\text { pathological features }\end{array}$ & $\begin{array}{l}\text { Serum and urine } \\
\text { electrophoresis }\end{array}$ & $\begin{array}{l}\text { Symptoms referable to } \\
\text { hip joint }\end{array}$ & $\begin{array}{l}\text { Radiological features of } \\
\text { hip joint }\end{array}$ \\
\hline $\begin{array}{l}\text { Case } 1 \text { Woman } 65 \text { years } \\
\text { with primary amyloidosis } \\
\text { Systemic amyloidosis } \\
\text { diagnosed on lymph node and } \\
\text { rib biopsy. Postmortem } \\
\text { examination showed } \\
\text { widespread amyloidosis. No } \\
\text { evidence of myeloma }\end{array}$ & $\begin{array}{l}\text { Serum: } \\
\text { Two paraproteins, } \\
\text { a complex of IgM with IgG } \\
\text { kappa and lambda, IgG } \\
\text { kappa }\end{array}$ & $\begin{array}{l}\text { Very longstanding bilateral } \\
\text { pain and stiffness necessitating } \\
\text { confinement to bed for } 18 \\
\text { months before death }\end{array}$ & $\begin{array}{l}\text { Bilateral protrusio acetabuli with } \\
\text { some loss of medial joint space. } \\
\text { Small osteophytes bilaterally } \\
\text { superiorly with some mild } \\
\text { degenerative changes. Multiple } \\
\text { small radiotranslucenies in both } \\
\text { femoral heads (in retrospect due to } \\
\text { amyloid deposits) }\end{array}$ \\
\hline $\begin{array}{l}\text { Case } 2 \text { Woman } 55 \text { years } \\
\text { with multiple myeloma } \\
\text { Pathological fracture of left } \\
\text { femoral neck two years after } \\
\text { diagnosis of myeloma, treated } \\
\text { by hip replacement. Bilateral } \\
\text { carpal tunnel syndromes and } \\
\text { pain in small joints of hands }\end{array}$ & $\begin{array}{l}\text { Serum electrophoresis: } \\
\text { Free monoclonal light } \\
\text { chain fragment } \\
\text { Urine: Bence-Jones } \\
\text { proteinuria of lambda type }\end{array}$ & $\begin{array}{l}\text { For nine months before } \\
\text { pathological fracture bilateral } \\
\text { pain and stiffness especially in } \\
\text { the mornings, worse on the left } \\
\text { side }\end{array}$ & $\begin{array}{l}\text { No obvious osteoarthrosis. } \\
\text { Multiple small radiotranslucencies } \\
\text { in left femoral head with } \\
\text { irregularity of medial and inferior } \\
\text { margins. (in retrospect first } \\
\text { appeared two years before fracture } \\
\text { and progressed) }\end{array}$ \\
\hline $\begin{array}{l}\text { Case } 3 \text { Woman } 88 \text { years } \\
\text { with traumatic fracture } \\
\text { Fractured neck of left femur } \\
\text { following a fall. Treated by hip } \\
\text { replacement. No evidence of } \\
\text { systemic amyloidosis }\end{array}$ & $\begin{array}{l}\text { Serum: no abnormality } \\
\text { Urine: no abnormality }\end{array}$ & $\begin{array}{l}\text { Vague history of widespread } \\
\text { aches and pains for many years }\end{array}$ & $\begin{array}{l}\text { Left hip, good joint space with } \\
\text { early osteophyte formation in } \\
\text { acetabulum }\end{array}$ \\
\hline $\begin{array}{l}\text { Case } 4 \text { Man } 70 \text { years } \\
\text { with traumatic fracture } \\
\text { Fractured neck of left femur } \\
\text { following a fall. Treated by hip } \\
\text { replacement. No evidence of } \\
\text { systemic amyloidosis }\end{array}$ & Serum: no abnormality & None & $\begin{array}{l}\text { Good joint space in left hip with } \\
\text { scattered loose bodies but no } \\
\text { osteophytes. Small defect superior } \\
\text { aspect of femoral head. Possible } \\
\text { avascular necrosis }\end{array}$ \\
\hline
\end{tabular}


Table 2 Pathological findings in femoral head

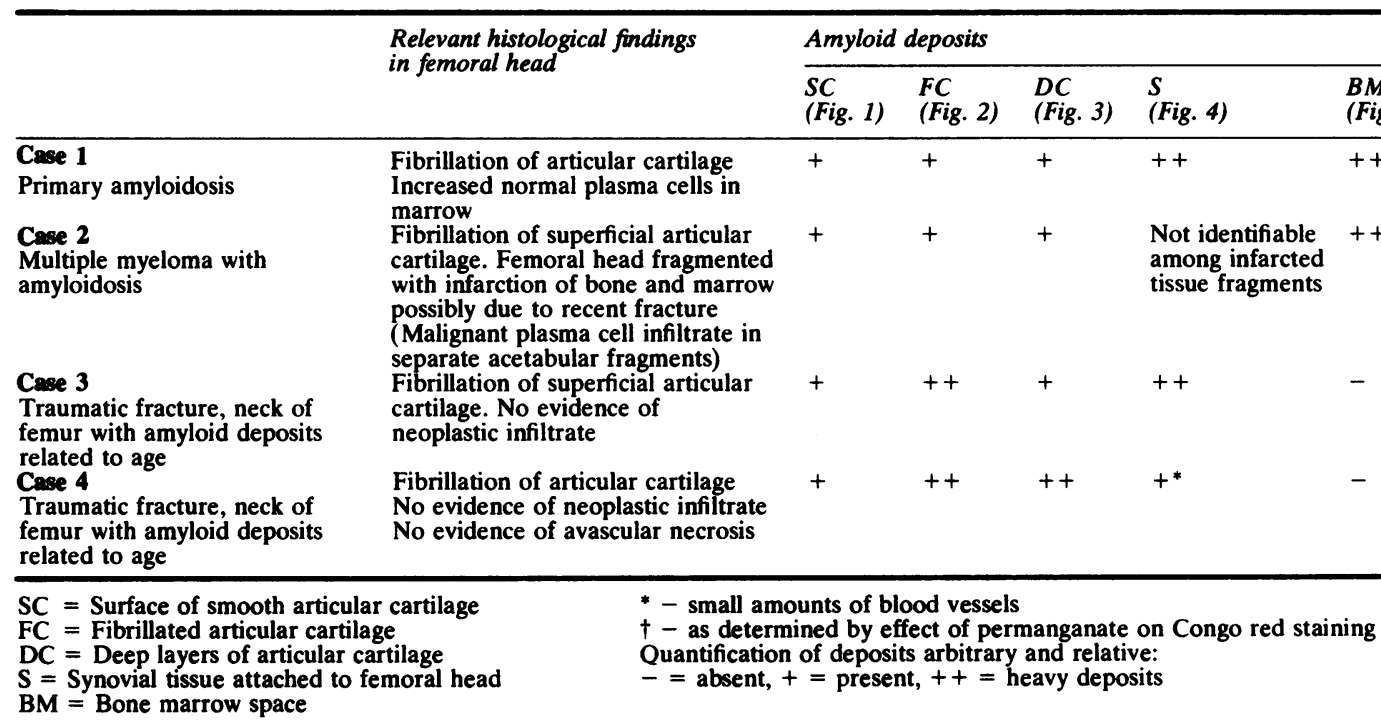

\section{Discussion}

The fact that all four patients show similar depositis of amyloid in articular cartilage adds weight to previous reports that the presence of amyloid in articular cartilage is no more than a phenomenon related to age, ${ }^{2-4}$ and, further, that it is in no way a specific

Figs. 1-5 Patterns of amyloid deposition in femoral head by Congo red staining (amyloid deposits dark areas arrowed).

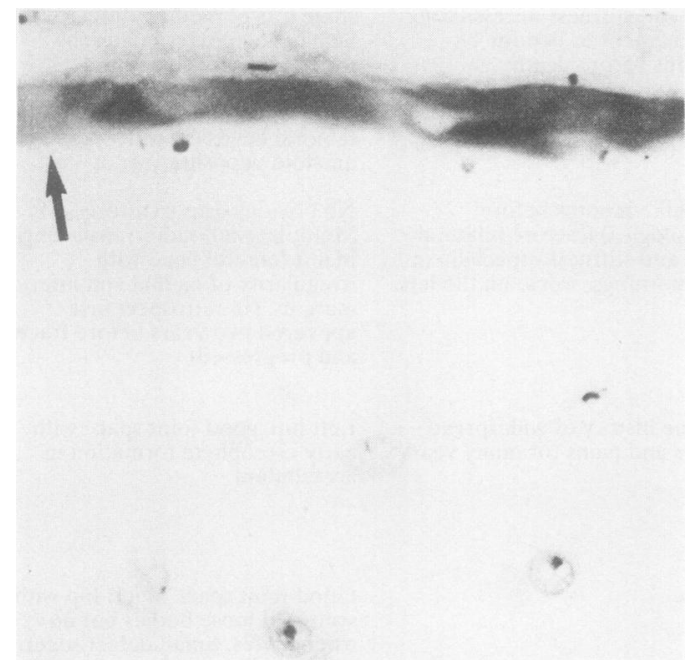

Fig. 1 Surface of articular cartilage showing linear deposits. $\times 375$. feature of generalised systemic amyloidosis, as has been previously stated.' The heavy synovial deposits in case 3 are of particular interest because similar deposits have been described in the arthropathy of a rheumatoid type that occurs in primary amyloidosis and multiple myeloma, ${ }^{7-11}$ but there was no evidence of either this type of arthropathy or generalised systemic amyloidosis in this case.

Thus deposits of amyloid in synovial tissue are another facet of amyloidosis related to age; even in quite large amounts they do not necessarily produce

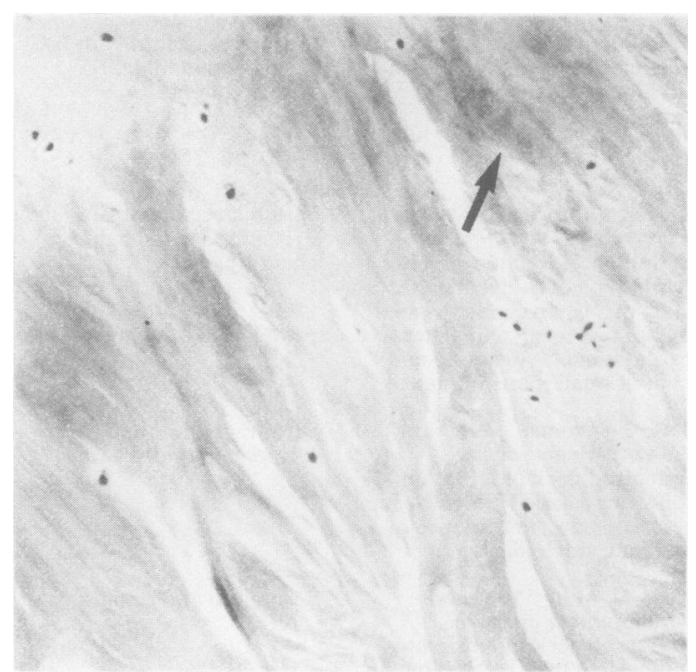

Fig. 2 Irregular deposits around fibrillated articular cartilage. $\times 375$. 


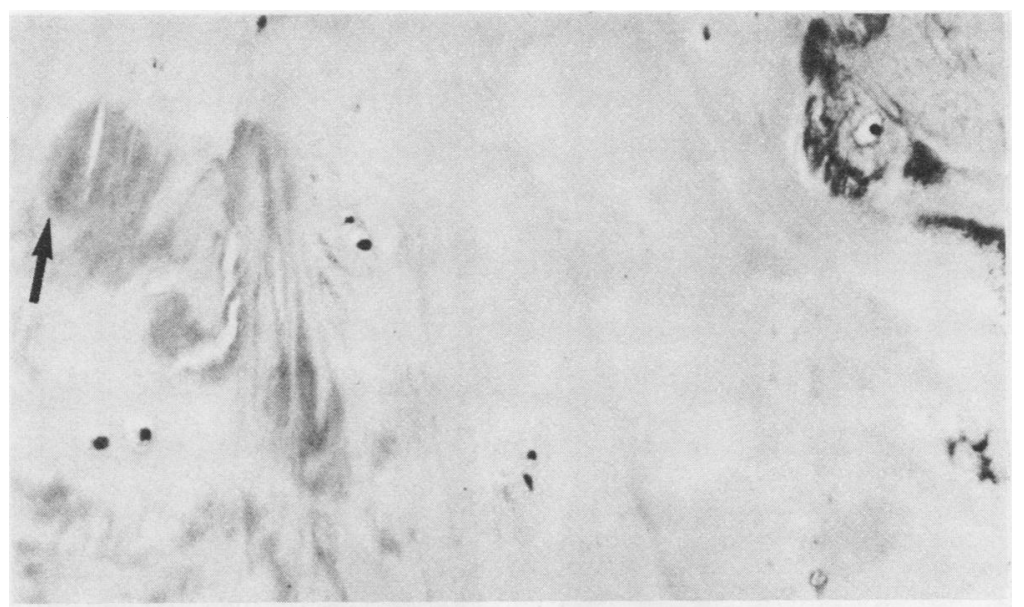

Fig. 3 Small nodular deposits deep to layers of articular cartilage (subchondral bone top right). $\times 240$.

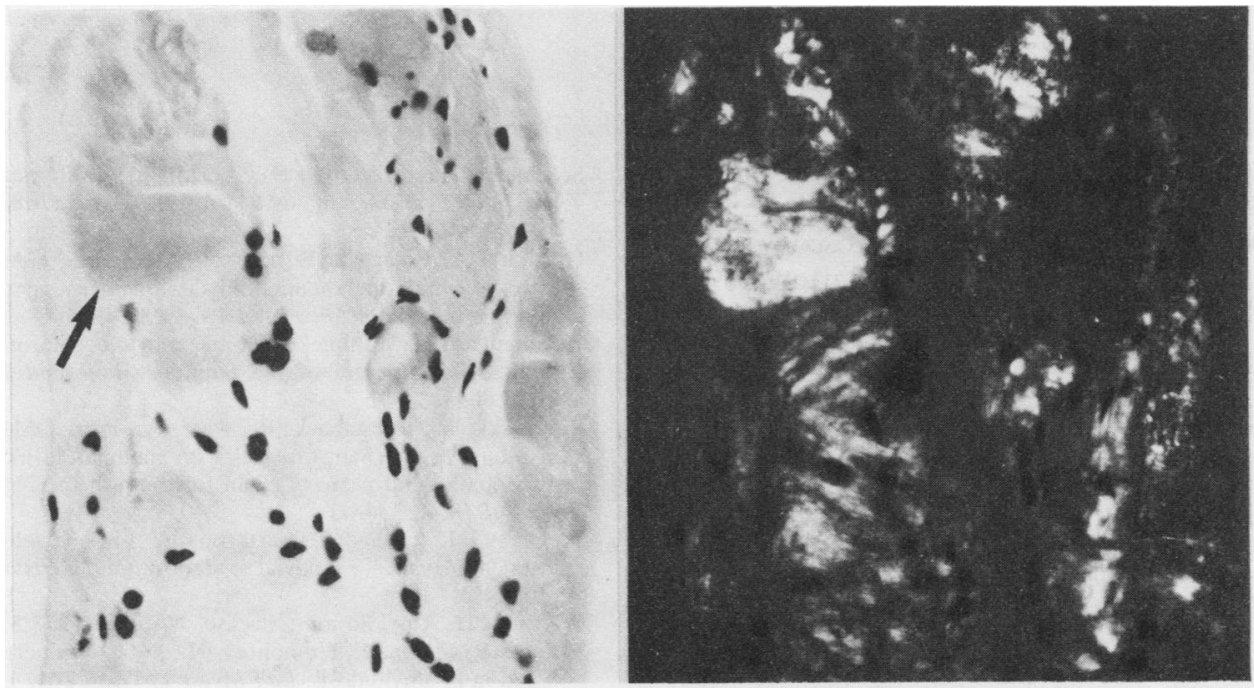

Fig. 4 Heavy synovial deposits (plain illumination left, cross polarised right). $\times 300$.

symptoms in large joints, though in generalised systemic amyloidosis the quantities deposited may be unusually large and produce palpable swellings around the joints.

In both patients with generalised systemic amyloidosis (cases 1 and 2) there were heavy deposits of amyloid in the bone marrow space extending up to the subchondral bone (Fig. 5). Such deposits were absent from cases 3 and 4 . It is therefore suggested that this type of deposit is restricted to generalised systemic amyloidosis. Such deposits in the juxta-articular bone marrow might in some way produce pain and stiffness in large joints such as the hip as part of an arthropathy of rheumatoid type. The presence of extensive amyloid deposits in the bone marrow, however, is clearly not necessarily associated with an arthropathy of a rheumatoid type: these deposits were widespread throughout the skeleton in case 1 , in which there was no evidence of an arthropathy syndrome. The subject clearly requires further study.

I thank the following from the department of histopathology and experimental pathology, Charing 


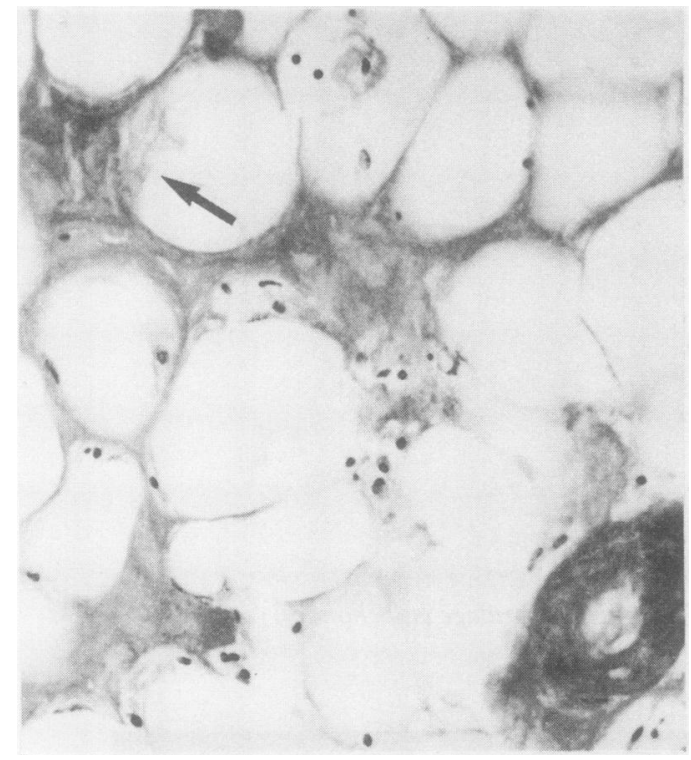

Fig. 5 Heavy bone marrow deposits. $\times 240$.

Cross and Westminster Medical School, for their help: Mr K James and Mr K Stevens for technical work; $\mathrm{Mr} \mathrm{T}$ Bull for electron microscopy; $\mathrm{Mr} \mathrm{R}$ Barnett for photography; Miss E Barton for secretarial help; Dr FJ Paradinas for providing material for case 1; and Dr B Fox for all his help and encouragement. Dr D Taylor (Department of Radiology, Charing Cross Hospital, Fulham) interpreted the radiographs in the four cases.

\section{References}

' Bywaters EGL, Dorling J. Amyloid deposits in articular cartilage. Ann Rheum Dis 1970;29:294-305.

${ }^{2}$ Stockwell RA. Stain distribution with alcian blue in articular cartilage. Ann Rheum Dis 1975;34 (supplement):17-8.

${ }^{3}$ Bartley CJ, Orford CR, Gardner DL. Amyloid in ageing articular cartilage. J Pathol 1985; 145:107A.

${ }^{4}$ Mitrovic DR, Stankovic A, Quintero M, Ryckewaert A. Amyloid deposits in human knee and hip joints. Rheumatol In 1985; 5: 83-9.

' Ishii T, Hosoda Y, Ikegami N, Hiroyuki S. Senile amyloid deposition. J Pathol 1983;139:1-22.

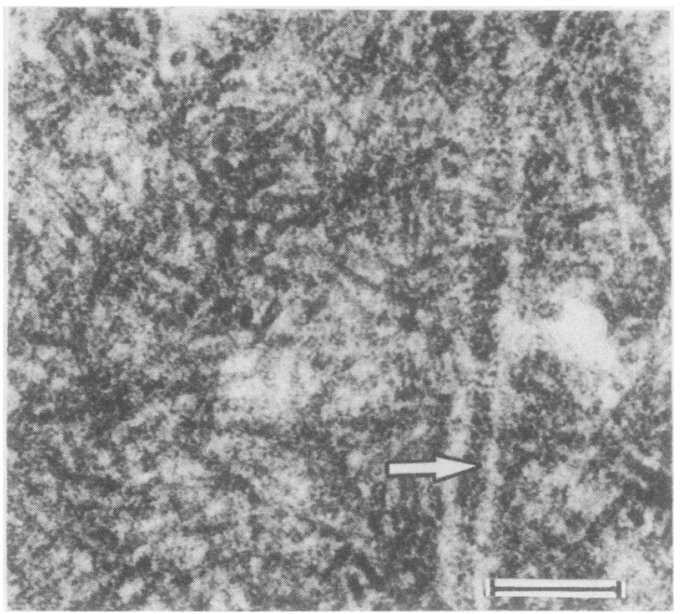

Fig. 6 Electron micrograph of articular cartilage amyloid deposit with admixed banded collagen fibre (arrowed). Bar mark $100 \mathrm{~nm}$.

- Sorensen KH, Christensen HE. Local amyloid formation in the hip joint capsule in osteoarthritis. Acta Orthop Scand 1973;44:460-6.

' Gordon DA, Pruzanski W, Ogryzlo MA, Little HA. Amyloid arthritis simulating rheumatoid disease in five patients with multiple myeloma. Am J Med 1973;55:142-54.

${ }^{8}$ Kavanaugh $\mathrm{JH}$. Multiple myeloma, amyloid arthropathy, and pathological fracture of the femur. J Bone and Joint Surg 1978;60A: $135-7$.

' Pruzanski W, Hasselback R, Katz A, Parr DM. Multiple myeloma (light chain disease) with rheumatoid-like amyloid arthropathy and $\mu$ heavy chain fragment in the serum. Am J Med 1978;65:334-41.

${ }^{10}$ French BT. Amyloid arthropathy in myelomatosisintracytoplasmic synovial deposition. Histopathology 1980;4:21-8.

"Wiernik PH. Amyloid joint disease. Medicine 1972;51:465-79.

${ }^{12}$ Wright JR, Calkins E, Humphrey RL. Potassium permanganate reaction in amyloidosis. Lab Invest 1977;36:274.

Requests for reprints to: Dr NRB Cary, Department of Histopathology and Experimental Pathology, Charing of Cross Hospital Medical School, Fulham Palace Road, London W6 8RF. 